Original Research Article

\title{
Phenotypic characterization and susceptibility of gram negative bacteria from surgical site infections in a tertiary care hospital
}

\author{
Akhilesh P. S. Tomar' ${ }^{1}$, Anjali Kushwah ${ }^{2 *}$
}

${ }^{1}$ Department of Microbiology, NSCB Medical College, Jabalpur, Madhya Pradesh, India ${ }^{2}$ Department of Pharmacology, Gajra Raja Medical College, Gwalior, Madhya Pradesh, India

Received: 02 May 2018

Accepted: 26 May 2018

\section{*Correspondence to: \\ Dr. Anjali Kushwah, \\ Email: dranjalitomar@ \\ gmail.com}

Copyright: (C) the author(s), publisher and licensee Medip Academy. This is an openaccess article distributed under the terms of the Creative Commons Attribution NonCommercial License, which permits unrestricted noncommercial use, distribution, and reproduction in any medium, provided the original work is properly cited.

\begin{abstract}
Background: Gram negative bacteria are the common isolates among the cases of Surgical Site Infections (SSI). Resistant and specially Multi Drug Resistant (MDR) Gram negative isolates are a serious challenge for the treatment to clinicians. Present study was undertaken for phenotypic characterization and susceptibility pattern of Gram negative bacterial isolates from cases of surgical site infections in a tertiary care institute.

Methods: This descriptive cross sectional hospital based study was conducted in a tertiary care teaching hospital over a period of one and half year from January 2012 to June 2013. Centers for disease control and prevention (CDC) SSI case definitions were used to label a case as SSI. Only culture proven cases, out of clinically suspected was included in the study for evaluation.

Results: During the study period a total of 5949 patients were operated and screened for SSI in the wards under surveillance. Out of which 556 were clinically suspected as a case of SSI. With 408 culture proven cases of SSI the rate of SSI in present study was $(6.86 \%)$. Rates of SSI were more in dirty $(22.54 \%)$ and contaminated (13.78\%) type of wounds. Among Gram negative bacterial isolates $(\mathrm{n}=343)$ from SSI, E. coli $(45.18 \%)$ was the commonest followed by Pseudomonas aeruginosa (16.03\%) and Klebsiella pneumoniae (13.42\%). Unpleasant trend in antimicrobial resistance observed during study is a serious concern.

Conclusions: The data presented in this study clearly indicate the continuous need of surveillance of SSI. This will clearly help health care personnel in curtailing down the incidences of SSI.
\end{abstract}

Keywords: Klebsiella pneumoniae, Multi drug resiatant organism, Pseudomonas aeruginosa, Surgical site infections

\section{INTRODUCTION}

Hospitalized patients encountered by the most common complications during their hospital stay are Health careassociated infections (HAIs). ${ }^{1}$ Despite of remarkable advances in infection control methods, HAIs remain a major public health problem and a significant cause of increased morbidity and mortality among hospitalized patients. In addition, HAIs are also responsible for inconvenience to the patients because of prolonged hospital stay that constitute an economic burden on patients and health care facility too. ${ }^{2-4}$ India has estimated prevalence of HAIs varies from 10-30\% in comparison of
HAIs prevalence worldwide varies from $3.8 \%$ to $18.6 \%$ depending upon the population surveyed. ${ }^{5}$ SSI contributes around a quarter of all health care associated infections. SSI have a remarkable impact on cost of therapy, which are associated with prolonged hospital stay, a high mortality and increased economic burden. ${ }^{6,7}$ Higher rates of infection often leads to increased rates of antimicrobial prescription which in turn contribute to increased antimicrobial resistance. ${ }^{6}$ Treatment of multi-drug resistant pathogens often requires costly second-and thirdline antimicrobials which may be associated with increased adverse reactions, increased risk of complications, prolonged illness, morbidity and mortality, as well as economic load on the patient. ${ }^{6}$ 
Microorganisms both from endogenous and exogenous sources are responsible for SSI. ${ }^{2}$ Both gram positive and gram negative organisms are responsible for HAIs. The Enterobacteriaceae family being the most commonly identified group overall among gram negative organisms responsible for SSI. Multidrug-resistant organisms are increasingly being reported. ${ }^{8}$

The present study was designed to study the phenotypic characterization and susceptibility of gram negative bacteria from Surgical Site Infections (SSI) in this geographic area. The purpose of the Antimicrobial Susceptibility Test (ABST) was:

- To guide the choice of the antimicrobial for the treatment.

- To provide surveillance data to monitor the resistance trend.

\section{METHODS}

This descriptive cross sectional hospital based study was conducted in a tertiary care teaching hospital over a period of one and half year from January 2012 to June 2013. The study was carried out in surgical ICU, general surgery, and obstetrics/ gynecology wards. Patients admitted in hospital and fitting in the definition of HAI were included in the study. Patients after one month of discharge and post transplant patients were not included in the study. In this study a HAI was an infection which occur $\geq 48 \mathrm{~h}$ or more after admission to hospital and which was not present or incubating on admission and was suspected when the patient had signs and symptoms according to one of the CDC definitions, or had one or more signs or symptoms included in one of the CDC definitions. CDC s SSI case definitions ${ }^{4}$ were used to label a case as SSI. Only culture proven cases, out of clinically suspected was included in the study for evaluation. Samples were collected from suspected SSI patients, 48 hours after admission and fulfilling the criteria for different types of SSI. ${ }^{4}$ Both active and passive surveillance methods were used for sample collection. Active surveillance was done by visiting various study areas daily along with infection control nurse. Passive surveillance was done by following the positive culture results obtained in microbiology laboratory to retrospective wards in the hospital and tried to look for HAI. Details of samples and patients were filled appropriately in predesigned Daily HAI Surveillance forms. The labelled specimens were transported to microbiology laboratory within $30 \mathrm{~min}$ of collection. Specimen were inoculated on appropriate culture media including blood agar, MacConkey agar, chocolate agar and incubated for $16-18 \mathrm{hrs}$ at $35-37^{\circ} \mathrm{C}$ by using standard laboratory techniques. ${ }^{9,10}$ Identification of bacteria was based on the colony characteristics of the organism i.e. colony morphology, hemolysis on blood agar, changes in the physical appearance of the differential media and enzyme activities of the organisms, Gram staining and biochemical tests. ${ }^{9,10}$
Antimicrobial sensitivity was performed on Muller Hinton agar plates by Kirby-Bauer disk diffusion method as per CLSI guidelines. ${ }^{9-11}$ Antibiotic discs were procured from HiMedia laboratories, Mumbai, India. Isolates were labeled susceptible, resistant and intermediate on the basis of CLSI disc zone interpretative criterion. ${ }^{11}$ All Gramnegative isolates were tested for ESBL and MBL production as per CLSI guidelines. ${ }^{9-11}$ ESBL positive Klebsiella pneumonia ATCC 700603 and ESBL negative Escherichia coli ATCC 25922 were included in the study for quality control of ESBL tests. ${ }^{11}$ Pseudomonas aeruginosa 27853 was used as the control for MBL tests. ${ }^{11}$ All the media and reagents were procured from Himedia, Mumbai, India.

\section{RESULTS}

A total of 5949 patients were operated and screened for SSI in the wards under surveillance during study period. The age range of operated patients was 10-94 years (Mean: 44.63 yrs). Out of which 556 were clinically suspected as a case of SSI. With 408 culture proven cases of SSI the rate of SSI in present study was $(6.86 \%)$ (Table 1). Females had more rates $(4.34 \%)$ of SSI in comparison with males $(2.52 \%)$ (Table 1). Rates of SSI were more in dirty $(22.54 \%)$ and contaminated $(13.78 \%)$ type of wounds (Table 2). Out of total 408 cases of culture proven cases of SSI, superficial surgical site infections $(75.74 \%)$ were more in comparison with deep surgical site infections (24.26\%) (Table 3). Rates of SSI were more in emergency surgeries (13.01\%) in comparison with elective surgeries $(5.16 \%)$ (Table 2). Among Gram negative bacterial isolates $(\mathrm{n}=343)$ from SSI, E. coli $(45.18 \%)$ was the commonest followed by Pseudomonas aeruginosa (16.03\%) and Klebsiella pneumoniae (13.42\%) (Table 4).

Table 1: Overall and gender wise distribution of SSI.

\begin{tabular}{|lll|}
\hline $\begin{array}{l}\text { Clinically } \\
\text { suspected SSI }\end{array}$ & $\begin{array}{l}\text { Culture } \\
\text { positive SSI }\end{array}$ & $\begin{array}{l}\text { Rate of SSI } \\
(\%)\end{array}$ \\
\hline 556 & 408 & 6.86 \\
\hline $\mathrm{M}=216$ & $\mathrm{M}=150$ & $\mathrm{M}=2.52$ \\
\hline $\mathrm{F}=340$ & $\mathrm{~F}=258$ & $\mathrm{~F}=4.34$ \\
\hline
\end{tabular}

Table 2: Rates of SSI according to type of wounds and timing of surgeries.

\begin{tabular}{|llll|} 
Type of wound & Total & $\begin{array}{l}\text { Culture } \\
\text { proven SSI }\end{array}$ & $\begin{array}{l}\text { SSI rate } \\
(\%)\end{array}$ \\
\hline Clean & 2929 & 89 & 3.04 \\
\hline Clean contaminated & 2593 & 245 & 9.45 \\
\hline Contaminated & 254 & 35 & 13.78 \\
\hline Dirty & 173 & 39 & 22.54 \\
\hline Elective & 4666 & 241 & 5.16 \\
\hline Emergency & 1283 & 167 & 24.26 \\
\hline
\end{tabular}

E. coli was the most common isolates among Gram negative bacteria isolated from the cases of SSIs, around Overall $(96.77 \%)$ of $E$. coli were resistant to ampicillin 
followed by $(91.61 \%)$ to cefuroxime and $(90.96 \%)$ to amoxycillin+ clavulanic acid. While none of the E. coli isolates were resistant to imipenem. Among aminoglycosides group resistance rates to gentamicin (42.58\%) were more in comparison with amikacin (13.54). Resistance rates to ciprofloxacin $(76.77 \%)$ were high.

Table 3: Distribution of different categories of SSI $(n=408)$.

\begin{tabular}{|lll|}
\hline Type of SSI & Culture positive SSI & $(\%)$ \\
\hline $\begin{array}{l}\text { Superficial surgical } \\
\text { site infections }\end{array}$ & 309 & 75.73 \\
\hline $\begin{array}{l}\text { Deep surgical site } \\
\text { infections }\end{array}$ & 99 & 24.26 \\
\hline Organ/ space & - & - \\
\hline
\end{tabular}

Table 4: Gram negative bacterial isolates from SSI $(n=343)$.

\begin{tabular}{|lll|}
\hline Microorganisms & Number & (\%) \\
\hline E. coli & 155 & 45.18 \\
\hline Pseudomonas aeruginosa & 55 & 16.03 \\
\hline Klebsiella pneumoniae & 46 & 13.42 \\
\hline Citrobacter freundii & 20 & 5.84 \\
\hline Citrobacter koseri & 18 & 5.25 \\
\hline Enterobacter aerogenes & 12 & 3.49 \\
\hline Klebsiella oxytoca & 10 & 2.92 \\
\hline Pseudomonas stutzeri & 09 & 2.62 \\
\hline Proteus mirabilis & 08 & 2.34 \\
\hline Proteus vulgaris & 03 & 0.87 \\
\hline Pseudomonas putida & 03 & 0.87 \\
\hline Acinetobacter baumanii & 02 & 0.58 \\
\hline Morganella morganii & 02 & 0.58 \\
\hline
\end{tabular}

Table 5: Resistance pattern of common Gram negative bacterial isolates from SSI ( $\%$ resistance).

\begin{tabular}{|c|c|c|c|c|c|c|c|}
\hline Antibiotics & $\begin{array}{l}\text { E. coli } \\
(n=155)\end{array}$ & $\begin{array}{l}\text { Pseudomonas } \\
\text { aeruginosa } \\
(\mathrm{n}=\mathbf{5 5})\end{array}$ & $\begin{array}{l}\text { Klebsiella } \\
\text { pneumoniae } \\
(\mathrm{n}=46)\end{array}$ & $\begin{array}{l}\text { Citrobacter } \\
\text { freudii } \\
(n=20)\end{array}$ & $\begin{array}{l}\text { Citrobacter } \\
\text { koseri } \\
(\mathrm{n}=\mathbf{1 8})\end{array}$ & $\begin{array}{l}\text { Enterobacter } \\
\text { aerogenes } \\
(\mathrm{n}=12)\end{array}$ & $\begin{array}{l}\text { Proteus } \\
\text { spp. } \\
(\mathrm{n}=11)\end{array}$ \\
\hline Ampicillin & $\begin{array}{l}150 \\
(96.77)\end{array}$ & ND & 45 (97.82) & $18(90)$ & $16(88.88)$ & $12(100)$ & $\begin{array}{l}11 \\
(100)\end{array}$ \\
\hline $\begin{array}{l}\text { Amoxycillin }+ \\
\text { Clavulanic acid }\end{array}$ & $\begin{array}{l}141 \\
(90.96)\end{array}$ & ND & $42(91.30)$ & $18(90)$ & $16(88.88)$ & $12(100)$ & $\begin{array}{l}10 \\
(90.90)\end{array}$ \\
\hline Piperacillin & $\begin{array}{l}104 \\
(67.09)\end{array}$ & $10(18.18)$ & $37(80.43)$ & $15(75)$ & $15(83.33)$ & $11(91.66)$ & $\begin{array}{l}05 \\
(45.45)\end{array}$ \\
\hline $\begin{array}{l}\text { Piperacillin + } \\
\text { Tazobactum }\end{array}$ & $\begin{array}{l}36 \\
(23.22)\end{array}$ & $06(10.90)$ & $19(41.30)$ & $12(60)$ & $07(38.88)$ & 05 (41.66) & $\begin{array}{l}03 \\
(27.27)\end{array}$ \\
\hline Cefazolin & $\begin{array}{l}128 \\
(82.58)\end{array}$ & ND & $41(89.13)$ & $17(85)$ & 14 (77.77) & $09(75)$ & $\begin{array}{l}10 \\
(90.90)\end{array}$ \\
\hline Cefepime & $\begin{array}{l}94 \\
(60.64)\end{array}$ & $19(34.54)$ & $36(78.26)$ & $14(70)$ & $12(66.66)$ & $09(75)$ & $\begin{array}{l}08 \\
(72.72)\end{array}$ \\
\hline Cefotaxime & $\begin{array}{l}118 \\
(76.12)\end{array}$ & ND & $41(89.13)$ & $17(85)$ & $15(83.33)$ & $12(100 \%)$ & $\begin{array}{l}09 \\
(81.81)\end{array}$ \\
\hline Cefoxitin & $\begin{array}{l}54 \\
(34.83)\end{array}$ & $16(29.09)$ & 27 (58.69) & $16(80)$ & $13(72.22)$ & 11 (91.66) & $\begin{array}{l}06 \\
(54.54)\end{array}$ \\
\hline Ceftazidime & $\begin{array}{l}105 \\
(67.74)\end{array}$ & $11(20)$ & 39 (84.78) & $16(80)$ & 14 (77.77) & $11(91.66)$ & $\begin{array}{l}09 \\
(81.81)\end{array}$ \\
\hline Cefoparazone & ND & $11(20)$ & ND & ND & ND & ND & ND \\
\hline Cefuroxime & $\begin{array}{l}155 \\
(91.61)\end{array}$ & ND & 43 (93.47) & $18(90)$ & $15(83.33)$ & $12(100)$ & $\begin{array}{l}11 \\
(100)\end{array}$ \\
\hline Imipenem & $00(00)$ & $00(00)$ & $01(2.17)$ & $00(00 \%)$ & $00(00)$ & $00(00)$ & $\begin{array}{l}01 \\
(9.09)\end{array}$ \\
\hline Amikacin & $\begin{array}{l}21 \\
(13.54)\end{array}$ & $15(27.27)$ & $20(43.47)$ & $09(45)$ & $07(38.88)$ & 05 (41.66) & $\begin{array}{l}04 \\
(36.36)\end{array}$ \\
\hline Gentamicin & $\begin{array}{l}66 \\
(42.58)\end{array}$ & $19(34.54)$ & $31(67.39)$ & $11(55)$ & $13(72.22)$ & $09(75)$ & $\begin{array}{l}08 \\
(72.72)\end{array}$ \\
\hline Ciprofloxacin & $\begin{array}{l}119 \\
(76.77)\end{array}$ & $24(43.63)$ & $40(86.95)$ & $15(75)$ & $13(72.22)$ & 11 (91.66) & $\begin{array}{l}07 \\
(63.63)\end{array}$ \\
\hline $\begin{array}{l}\text { Trimethoprim/ } \\
\text { Sulfametho-xazole }\end{array}$ & $\begin{array}{l}41 \\
(26.45)\end{array}$ & ND & $26(56.52)$ & $14(70)$ & $10(55.55)$ & $07(58.33)$ & $\begin{array}{l}07 \\
(63.63)\end{array}$ \\
\hline
\end{tabular}


Pseudomonas aeruginosa was the second most common isolates and it shows around $(43.63 \%)$ resistance to Ciprofloxacin followed by $(34.54 \%)$ to cefepime and (20\%) to cefoparazone and ceftazidime.

While none of the Pseudomonas aeruginosa isolates were resistant to imipenem. Among aminoglycosides group resistance rates to gentamicin $(34.54 \%)$ were more in comparison with amikacin $(27.27 \%)$ (Table 5). Overall (40\%) isolates of E. coli and $(54.34 \%)$ isolates of Klebsiella pneumoniae were ESBL producers, (2.17\%) isolates of Klebsiella pneumoniae were MBL producers and $(74.84 \%)$ of E. coli, $(98.21 \%)$ of Klebsiella pneumoniae and $(21.81 \%)$ of Pseudomonas aeruginosa were considered as MDR (Figure 1).

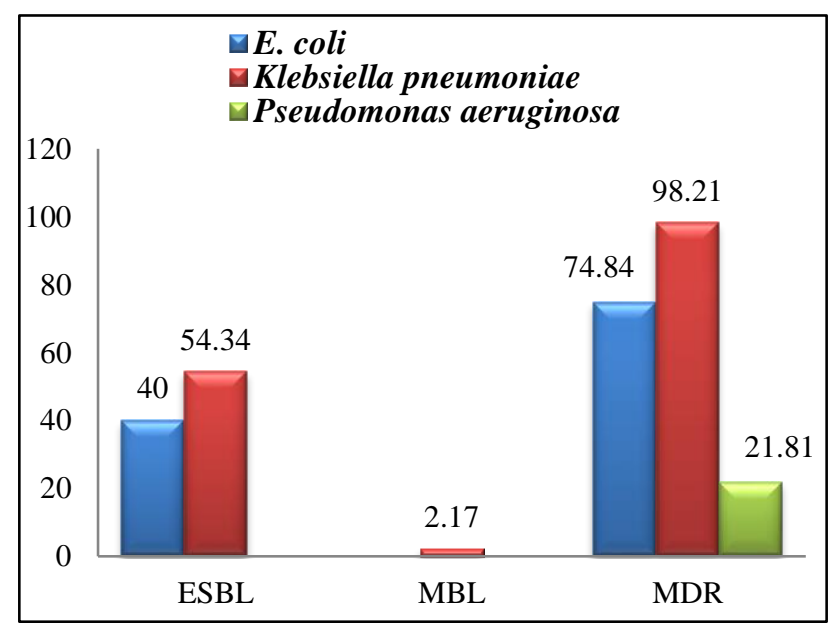

Figure 1: ESBL, MBL and MDR among Gram negative bacterial isolates of SSI.

\section{DISCUSSION}

The surgical site infection rates reported by different workers have considerable difference. The overall infection rate in the present study was (6.86\%) and compares favorably with other reported rates ranging from $(2.5 \%$ to $41.9 \%){ }^{12}$ while the rate is much higher than the overall average SSI rate of $(2.61 \%)$, published by the NNISS, USA. ${ }^{13}$

The higher infection rate may be because of poor awareness about the HAI and ineffective infection control practices. Number of studies carried out in India indicates an overall infection rate of $4.04 \%$ to $30 \%$ for clean surgeries and $10.06 \%$ to $45 \%$ for clean contaminated surgeries. ${ }^{12}$ Findings in the present study showed that there was a significant rise in infection with increased degree of operative contamination; rate of infection from clean wounds was $(3.04 \%)$ while in dirty wounds it was $(22.54 \%)$. Similar findings were reported by with Lilani et al. ${ }^{12}$ Emergency operations were more likely, than routine to be infected. In present study the rate of SSI (13.01\%) in emergency surgeries were higher than the rate of SSI $(5.16 \%)$ in elective surgeries. Other studies have also demonstrated higher infection rate in the emergency operations, this might be because of inappropriate preoperative preparation and the severity of underlying condition that required emergency procedure. ${ }^{12,14-16}$ Present study shows that $E$. coli was the leading cause of SSI followed by Pseudomonas aeruginosa and Klebsiella pneumonia (Table 4). These results are in accordance with few studies while differ from some other studies. ${ }^{12,14,17-19}$

A total of $(96.77 \%)$ of $E$. coli isolates were resistant to ampicillin the present study. While Sikka et al, reported (98.6\%) resistance to ampicillin. ${ }^{20}$ Thus we can say that the ampicillin which was previously sensitive to many Gram-negative bacteria is now resistant to almost all. Difference between the percent resistance rate of amikacin and gentamicin $(13.54 \%$ vs $42.58 \%)$ is in accordance with the result of sikka et al $(58.3 \%$ vs $95.8 \%) .{ }^{20}$ Resistance pattern of $E$. coli in this study as compared to Sikka et al, were for ciprofloxacin (76.77 vs $93.1 \%)$, imipenem $(00 \%$ vs $4.2 \%$ ), amoxicillin/ clavulanic acid (90.96\% vs $84.7 \%)$, ceftazidime $(67.74 \%$ vs $91.6 \%)$, cefotaxime $(76.12 \%$ vs $94.4 \%)$ and cefepime $(60.64 \%$ vs $91.6 \%) .{ }^{20}$ So, increased antibiotic resistance pattern noted for $E$. coli suggests its importance for hospital acquired infection. Resistance pattern of $K$. pneumoniae in this study as compared to Sikka et al, were for ampicillin (97.82\% vs $100 \%)$, ciprofloxacin $(86.95 \%$ vs $88.2 \%)$, imipenem $(2.17 \%$ vs $00 \%$ ), amoxicillin/ clavulanic acid (91.30\% vs $88.2 \%)$, ceftazidime $(84.78 \%$ vs $100 \%)$, cefotaxime $(89.13 \%$ vs $94.1 \%)$, cefepime $(78.26 \%$ vs $82.3 \%)$, amikacin $(43.47 \%$ vs $76.4 \%)$ and gentamicin $(67.39 \%$ vs $94.1 \%){ }^{20}$ Resistance pattern of Pseudomonas aeruginosa in this study as compared to Sikka et al, were for piperacilli/tazobactum (10.90\% vs 50\%), imipenem (00\% vs $00 \%)$, ceftazidime $(20 \%$ vs $87.5 \%)$, cefepime $(34.54 \%$ vs $87.5 \%)$, amikacin $(27.27 \%$ vs $75 \%)$ and gentamicin $(34.54 \%$ vs $100 \%) .{ }^{20}$ Resistance to Pseudomonas isolates from SSI in present study was lower in comparison to Sikka et al. ${ }^{20}$ Susceptibility pattern of common isolates in present study varied from the results of other observers. ${ }^{21-}$ 25

Among the species E. coli and $K$. pneumonia the development of resistance to extended-spectrum cephalosporins is becoming a serious trend wordwide. ${ }^{26,27}$ Such resistance is most often due to the production of extended-spectrum $\beta$-lactamases (ESBLs). ${ }^{26,27}$ The data from the Tigecycline Evaluation and Surveillance Trial (TEST) global surveillance database shows that the rate of the ESBL production was the highest among the $K$. pneumoniae isolates. ${ }^{28}$

Previous studies which have documented the prevalence of ESBL in India, as 24.8-63.8\% among the E.coli isolates, at $10.1-76.2 \%$ among the Klebsiella pneumoniae and at 14.4$70.5 \%$ among Proteus mirabilis. ${ }^{29}$ In the present study the rate of ESBL producers among $E$. coli isolated from cases of SSI were (40\%) and K. pneumoniae (54.34\%). Analysis of data from National Nosocomial Infection Surveillance (NNIS) system demonstrate that only $2.3 \%$ 
Enterobacteriaceae isolates tested nonsusceptible to imipenem. ${ }^{30}$ However, rate of Carbapenem Resistant Enerobacteriaceae (CRE) is increasing worldwide. In the Meropenem Yearly Susceptibility Test Information Collection Program, meropenem resistance among clinical isolates of Klebsiella pneumoniae increased significantly from $0.6 \%$ in 2004 to $5.6 \%$ in $2008 .{ }^{30}$ Among isolates reported NHSN in 2009-2010, carbapenem resistance was up to $(<1 \%)$ to $K$. pneumoniael oxytoca and $(<1 \%)$ to $E$. coli. ${ }^{31}$ In the present study the rate of MBL producers among K. pneumoniae isolates were $(2.17 \%)$. Results are comparable with the NHSN 2009-2010 data. ${ }^{31}$ Indian studies have documented the prevalence rate ranged from $1-11 \%$ among Enterobacteriaceae. ${ }^{29}$

No isolates of E. coli and Pseudomonas aeruginosa were found resistant to Carbapenem. Though the rate is low in comparison to other studies but still the emergence of resistance for carbapenem group of antibiotics in present study warranted the judicious use which will help in, to prevent further development of resistance.

Isolates resistant to three or more antimicrobial classes were considered Multi Drug Resistant (MDR) in the present study. ${ }^{32-35}$ Results of current study documented that $(74.84 \%)$ of $E$. coli isolates and (98.21\%) $K$. pneumoniae isolates were MDR. MDR in P. aeruginosa is usually defined as resistance to three or more of the following antimicrobial agents: antipseudomonal penicillins (e.g., piperacillin), antipseudomonal cephalosporins (e.g., ceftazidime), fluoroquinolones (e.g., ciprofloxacin), carbapenems (imipenem, meropenem, and doripenem), and the aminoglycosides (gentamicin, tobramycin, or amikacin). The prevalence of MDR Pseudomonas aeruginosa in various parts of the world ranged from $(1.6-50 \%){ }^{24,34,36}$ In the present study the prevalence rate of MDR Pseudomonas aeruginosa were $(21.81 \%)$. These results are comparable with the data from the different parts of the world. ${ }^{24,34,36}$

So, this study finding supports the unpleasant trends in antibiotic resistance, indicating decreasing efficacy of various antibiotic classes against gram negative bacilli. The increased prevalence of extended-spectrum betalactamases may contribute to the finding of multidrug resistance. Hospital set up, injudicious use of antimicrobials and case materials determines the rate of SSI in any hospital. Antibiogram might be varying depending on the study group and hospital set up.

Overall, the pattern of antimicrobial resistance among Gram negative isolates from SSI in the present study emphasized the need for:

- Urgent action for the implementation of infection control policies.

- Urgent action to be taken to prevent the dissemination of MDR Gram negative pathogens.

- Measures to bring down injudicious use of antimicrobials.
- $\quad$ Provide a healthcare set up that is safe for patients.

\section{CONCLUSION}

The data presented in this study clearly indicate the gravity of antibiotic resistance. Surveillance of SSI and antibiotic resistance in SSI causing pathogens is a need of future. Hence the data generated will help to treating physician and/ or surgeon in getting the knowledge of current trends of SSI in this setup that ultimately help them in the selection of appropriate antimicrobial therapy, thereby decreases length of hospital stay, cost of therapy, morbidity and mortality. Appropriate and adequate antimicrobial treatment of SSI cases based on microbiological culture report is need of time.

Funding: No funding sources

Conflict of interest: None declared

Ethical approval: The study was approved by the Institutional Ethics Committee

\section{REFERENCES}

1. Burke JP. Infection control-a problem for patient safety. N Engl J Med. 2003;348:651-6.

2. World Health Organization. Report on the burden of endemic health care-associated infection worldwide: clean care is safer care. (WHO Document Production Services: Geneva, Switzerland, 2011).

3. Raka L. Prevention and control of hospital-related infections in low and middle-income countries. The Open Infectious Disease Journal. 2010;4:125-31.

4. Samuel, $S$ et al. Nosocomial infections and the challenges of control in developing countries. Afr J Cln Exper microbial. 2010;11:102-10.

5. de Lissovoy G, Fraeman K, Hutchins V, Murphy D, Song D, Vaughn BB. Surgical site infection: incidence and impact on hospital utilization and treatment costs. Am J Infect Control. 2009 Jun 1;37(5):387-97.

6. World Health Organization. The evolving threat of antimicrobial resistance: options foraction. (WHO Library Cataloguing-in-Publication Data: Geneva, Switzerland, 2012).

7. Centre for Disease prevention and control. Types of health care-associated infections. (CDC 2012). Available at: http://www.cdc.gov/HAI/infection types.html.

8. Yokoe DS, Anderson DJ, Berenholtz SM, Calfee DP, Dubberke ER, Ellingson KD, et al. A compendium of strategies to prevent healthcare-associated infections in acute care hospitals: 2014 updates. American journal of infection control. 2014 Aug 1;42(8):820-8.

9. Koneman EW, Allen S, Janda W, Schreckenberger P, Winn WC. Color Atlas and Text book of Diagnostic Microbiology, $6^{\text {th }}$ Edn. New York: Lippincott; 2006.

10. Collee JG, Marmion BP, Fraser AG, Simmons A, Eds, Mackie \& McCartney Practical Medical Microbiology, $14^{\text {th }}$ Edition, Churchill Livingstone, New York, 11:245-258,4:151-177. 
11. CLSI. Performance Standards for Antimicrobial Susceptibility Testing; Twentieth Informational Supplement. CLSI document M100-S20. Wayne, PA: Clinical and Laboratory Standards Institute; 2010.

12. Lilani SP, Jangle N, Chowdhary A, Daver GB. Surgical site infection in clean and clean-contaminated cases. Indian J of Med Microbiol. 2005;23:249-52.

13. National Nosocomial Infections Surveillance System. National Nosocomial Infections Surveillance (NNIS) System Report, data summary from January 1992June 2001, issued August 2001. Am J Infect Control. 2001;29:404-21.

14. Tietjen L, Bossemeyer D, McIntosh N. Infection Prevention. Guidelines for Healthcare Facilities with Limited Resources. Baltimore, MD: JHPIEGO; 2003.

15. Weinstein R. Hospital-acquired infections. In: Kasper DL, Braunwald E, Fauci AS, Hauser SL, Longo DL, Jameson JL, Isselbacher KJ (eds.) Harrison's Principles of Internal Medicine. $16^{\text {th }}$ Ed. New York: McGraw Hill; 2004.

16. Cheadle W. Risk factors for surgical site infection. Surg Infect (Larchmt). 2006;7:7-11.

17. Auerbach AD. Prevention of surgical site infections. In: Shojania KG, Duncan BW, McDonald KM, Wachter RM (eds). Making Health Care Safer A Critical Analysis of Patient Safety Practices. Evidence Report/Technology Assessment, No. 43. Rockville, MD: Agency for Healthcare Research and Quality; 2001.

18. National Noscomial Infections Surveillance. National Nosocomial Infections Surveillance (NNIS) System Report, data summary from January 1992 through June 2004, issued October 2004. Am J Infect Control. 2004;32:470-85.

19. Owens CD, Stoessel K. Surgical site infections: epidemiology, microbiology and prevention. J Hosp Infect. 2008;70:3-10.

20. Sikka R, Mann JK, Deep, Vashist MG, Chaudhary U, Deep A. Prevalence and Antibiotic Sensitivity Pattern of Bacteria Isolated from Nosocomial Infections in a Surgical Ward. Indian J of Clin Pract. 2012;22:519-25.

21. Raja NS, Singh NN. Antimicrobial susceptibility pattern of clinical isolates of Pseudomonas aeruginosa in tertiary care hospital. J Microbiol Imm Infect. 2007;40:45-9.

22. Weber SG, Miller RR, pereneevich EN, Tolentino J, Meltzer D, Pitrak D, et al. Prevalence of antimicrobial resistant bacteria isolated from older versus younger hospitalized adults: Results of a two centre study. J Antimicrob Chemother. 2009;64:1291-8.

23. Fadeyi A, Akanbi AA, Nwabuisi C, Onile BA. Antibiotic disc sensitivity pattern of Pseudomonas aeruginosa isolates obtained from clinical specimen in Ilorin, Nigeria. Afr J Med. 2005;34:303-6.

24. Gales AC, Jones RN, Turnidge J, Rennie R, Ramphal R. Characterization of Pseudomonas aeruginosa: occurrence rate, antimicrobial susceptibility pattern and molecular typing in the global sentry antimicrobial surveillance program 1997-1999. Clinic Infect Dis. 2001;32:146-55.

25. Van Eldere J. Multicentre surveillance of Pseudomonas aeruginosa susceptibility patterns in nosocomial infections. J Antimicrob Chemother. 2003;51:347-52.

26. Bradford PA. Extended-spectrum beta-lactamases in the $21^{\text {st }}$ century: characterization, epidemiology, and detection of this important resistance threat. Clin. Microbiol. Rev. 2001;14:933-51.

27. Livermore DM. Woodford. The beta-lactamase threat in Enterobacteriaceae, Pseudomonas and Acinetobacter. Trends Microbiol. 2006;14:413-20.

28. Dhillon RH, Clark J. ESBLs: a clear and present danger?. Critical care research and practice. 2012;2012.

29. Thakuria B, Lahon K. The Beta Lactam Antibiotics as an Emperical Therapy in a Developing Country: An Update on Their Current Status and recommendations to Counter the Resistance against Them. J of Cli and Diag Resear. 2013;7:1207-14.

30. Gupta N, Limbago B, Patel JB, Kallen AJ. Carbapenem-Resistant Enterobacteriaceae: Epidemiology and Prevention. Clinical Infectious Disease. 2011;53:60-67.

31. Sievert DM, Ricks P, Edwards JR, Schneider A, Patel J, Srinivasan A, et al. Antimicrobial-resistant pathogens associated with healthcare-associated infections summary of data reported to the National Healthcare Safety Network at the Centers for Disease Control and Prevention, 2009-2010. Infection Control \& Hospital Epidemiology. 2013 Jan;34(1):1-4.

32. Andrade SS, Jones RN, Gales AC, Sader HS. Increasing prevalence of antimicrobial resistance among Pseudomonas aeruginosa isolates in Latin American medical centres: 5 year report of the SENTRY Antimicrobial Surveillance Program (19972001). J Antimicrob Chemother. 2003;52:140-41.

33. Kallen AJ, Hidron AI, Patel J, Srinivasan A. Multidrug resistance among gram-negative pathogens that caused healthcare-associated infections reported to the National Healthcare Safety Network, 2006-2008. Infect Control Hosp Epidemiol. 2010;31:528-31.

34. Falagas ME, Koletsi PK, Bliziotis IA. The diversity of definitions of multidrug-resistant (MDR) and pandrug-resistant (PDR) Acinetobacter baumannii and Pseudomonas aeruginosa. J Med Microbiol. 2006;55:1619-29.

35. Gould IM. The epidemiology of antibiotic resistance. Int J Antimicrob Agents. 2008;32:2-9.

36. Giske CG, Monnet DL, Cars O, Carmeli Y. Clinical and economic impact of common multidrug-resistant gram-negative bacilli. Antimicrobial agents and chemotherapy. 2008 Mar 1;52(3):813-21.

Cite this article as: Tomar APS, Kushwah A. Phenotypic characterization and susceptibility of gram negative bacteria from surgical site infections in a tertiary care hospital. Int J Basic Clin Pharmacol 2018;7:1371-6. 